\title{
Medication swallowing difficulties in people without dysphagia
}

\author{
Laís Flavia Souza \\ https://orcid.org/0000-0001-8504-5870 \\ Weslania Viviane Nascimento \\ https://orcid.org/0000-0003-1267-3475 \\ Leda Maria Tavares Alves \\ https://orcid.org/0000-0002-4125-3747 \\ Ana Cristina Viana Silva \\ https://orcid.org/0000-0002-1744-2804 \\ Rachel Aguiar Cassiani \\ https://orcid.org/0000-0002-6100-7025 \\ Dauana Cassia Alves \\ https://orcid.org/0000-0003-0198-3531 \\ Roberto Oliveira Dantas \\ https://orcid.org/0000-0003-2183-0815
}

Universidade de São Paulo, Faculdade de Medicina de Ribeirão Preto, Ribeirão Preto, São Paulo, Brasil.

Conflict of interests: Nonexistent

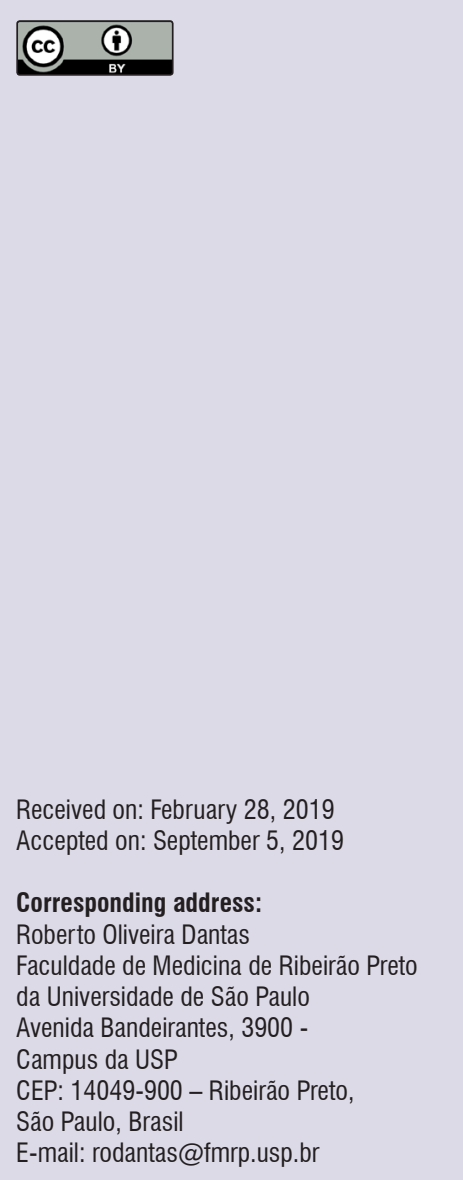

\section{ABSTRACT}

Objective: to assess the difficulty in swallowing medications and correlate it with age and gender in healthy adults and elderly.

Methods: a total of 439 asymptomatic healthy volunteers (270 females and 169 males), who were not taking any medication on a regular basis, aged from 20 to 84 years, were questioned as for dysphagia, by using the Eating Assessment Tool (EAT10). Question number five of the EAT-10, specifically, approached the difficulty in swallowing drugs, considering zero as "no swallowing problem" and 1 to 4 as "some degree of difficulty" (4 as great difficulty).The chi-square test (x2) was used for the statistical analysis.

Results: a total of $365(83 \%)$ volunteers reported having no difficulty in swallowing medications ( $89 \%$ of men and $80 \%$ of women), whereas 74 (17\%) reported some degree of difficulty ( $11 \%$ of men and $20 \%$ of women) $(p=0.01)$. These represented $20 \%$ of those aged between 20 and 49 , and $9 \%$ of those aged 50 and over $(p=0.02)$. Conclusion: in this study, it was observed that both age and gender influence on medication swallowing, a difficulty more frequent among women and young adults. Some degree of difficulty was reported by $17 \%$ of the volunteers.

Keywords: Swallowing; Swallowing Disorders; Oral Administration; Aging 


\section{INTRODUCTION}

Swallowing is a dynamic and complex process, in which breathing and gastrointestinal tract muscles are involved, coordinated by the cortex, brainstem and brain nerves ${ }^{1,2}$. Some factors, besides illnesses, may modify the swallowing process, such as volume and consistency of food bolus ${ }^{3,4}$, In addition to the person's gender $^{5-7}$ and age ${ }^{8,9}$.

The elderly population present risk of swallowing dynamics alterations due to the structural and functional changes common to the aging process ${ }^{8,10,11}$, as well as the greater prevalence of illnesses that cause dysphagia, such as stroke, Parkinson's disease and Alzheimer ${ }^{8,10}$.

In spite of the many studies reporting food swallowing difficulties, no studies carried out in Brazil with data regarding medication swallowing difficulties were found. In one study carried out in Germany, $37.4 \%$ of the participants reported having already had problems at some moment to swallow tablets, capsules or caplets; furthermore, $24.2 \%$ reported that such difficulty was frequent, and, in $70.4 \%$ of these cases, the difficulty had not been detected by the attending physician ${ }^{12}$. A similar result was found in a study carried out in the United States, in which half the population regularly made an effort to swallow the tablets ${ }^{13}$.

Medications are frequently modified, macerated, broken or opened (capsules) to aid in administration. Such changes, when not made under medical and/or pharmaceutical guidance, may limit the efficacy of the medication and cause damage to health ${ }^{13,14}$.

The acceptability of solid oral medications is related to its physical characteristics ${ }^{15}$. The reasons pointed out to concerning the difficulty in swallowing these medications are related to size $(74.6 \%)$, surface $(70.5 \%)$, shape $(43.5 \%)$, and flavor $(22.1 \%)$ of the tablets and capsules $^{16}$.

Researches on the swallowing of tablets, capsules and caplets are essential both for the elderly population and the younger one, which many times suffer from this difficulty.

The Eating Assessment Tool (EAT-10) is a selfevaluation instrument with 10 questions about functionality, emotional impact and physical symptoms related to swallowing difficulties ${ }^{17}$, and it helps to identify risks and symptoms of dysphagia for both foods and medications ${ }^{18}$.

The purpose of this study was to assess, by means of the EAT-10, the degree of medication swallowing difficulty, and to relate it to age and gender of young adults and elderly, neither diagnosed with dysphagia, nor any illness that may cause dysphagia. The hypothesis is that, in the population encompassed in the investigation, both age and gender may have an influence on the frequency of dysphagia for medications.

\section{METHODS}

This was an observational study carried out in five towns of the state of São Paulo between 2015 and 2017. The results were centralized and coordinated at the Clinics Hospital of the School of Medicine in Ribeirão Preto - University of São Paulo. The investigation was approved by the Research Ethics Committee of the institution, process number 9635/2013. The volunteers were instructed about the objectives and methods of the research, and signed Informed Consent Form.

Some 439 volunteers were assessed, being 270 females (61.5\%) and 169 males (38.5\%), aged from 20 to 84 years (average of 40 years); none of them had diseases or symptoms, nor took medications orally on a regular basis. People with acute or chronic diseases, or who took medications regularly, were excluded. Of the volunteers, $315(72 \%)$ were between 20 and 49 years old, 99 (22\%) were between 50 and 69, and 25 (6\%) were between 70 and 84 years old. The people interviewed were not patients of hospitals or clinics, and were assessed in public places, workplaces or recreation areas; they performed their daily tasks independently, lived outside the hospital environment, and had no restriction as to physical activities and to the ingestion of any food consistency.

The instrument EAT-10 was applied to all the volunteers, who were instructed to answer all the questions. The questions of the EAT-10 questionnaire ${ }^{17}$ were translated from the original into Portuguese and validated ${ }^{18}$ : 1) My swallowing problem has caused me to lose weight; 2) My swallowing problem interferes with my ability to go out for meals; 3) Swallowing liquids takes extra effort; 4) Swallowing solids takes extra effort; 5) Swallowing pills takes extra effort; 6) Swallowing is painful; 7) The pleasure of eating is affected by my swallowing; 8) When I swallow food sticks in my throat; 9) I cough when I eat; 10) Swallowing is stressful. The test has good sensitivity and specificity for the detection of dysphagia ${ }^{19}$, and has been used in many languages.

Question number five deals specifically with the difficulty to swallow medications. The subjects were instructed to answer according to difficulties experienced, and indicate the assertion that best defined their difficulty, in a scale ranging from zero (it's not a 
problem) to four (it's a very serious problem). When necessary, the questions were clarified to the volunteers, who marked their answers on the questionnaire or answered them after being read by the researcher.

Answers marked 1 to 4 were considered as difficulty in swallowing medications. The chi-squared test $\left(x^{2}\right)$ was used for the statistical analysis correlating the research's subject's degree of difficulty to their gender and age.

\section{RESULTS}

Regarding the question on the difficulty to swallow medications, 365 (83\%) answered 0, whereas 74 (17\%) reported some degree of difficulty (answers from 1 to 4$)$.

Among those who reported some degree of difficulty, $55(20 \%)$ were women and $19(11 \%)$, men ( $p=$ $0.01)$; also, $63(20 \%)$ were aged from 20 to 49 years, and $11(9 \%)$ were aged 50 years or over $(p=0.02)$. Furthermore, $45(61 \%)$ indicated option 1, 15 (20\%) indicated option 2, 12 (16\%) indicated option 3, and 2 (3\%) indicated option 4. Option zero (no difficulty) was indicated by $80 \%$ of women and $89 \%$ of men; and by $80 \%$ of those aged between 20 and 49 years, $90 \%$ of those between 50 and 69 years old, and $96 \%$ of those between 70 and 84 years old.

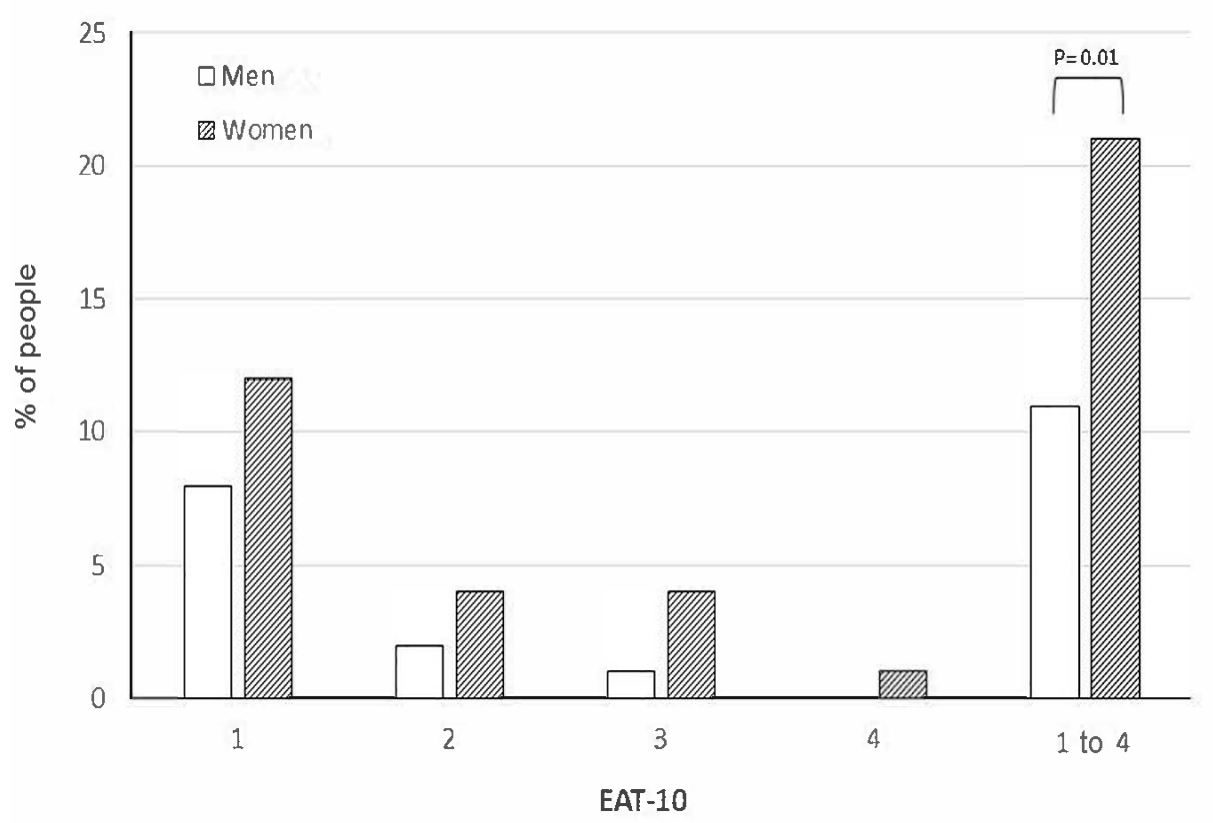

Figure 1. Results of answers given to question 5 (difficulty in swallowing medication) of the Eating Assessment Tool (EAT-10) in percentage of men and women

There was no statistical difference $(p=0.12)$ in the frequency of swallowing difficulty in the degrees 1 to 4 between men and women, or between the age groups $(p=0.12)$. However, when the answers zero (no difficulty) and the 1 to 4 (with difficulty) were considered, there was significant difference regarding both gender (difficulty more frequent among women $-p=0.01$ ) (Figure 1), and age factor (difficulty more frequent among those aged between 20 and 49 years) $(p=$ 0.02) (Figure 2). 


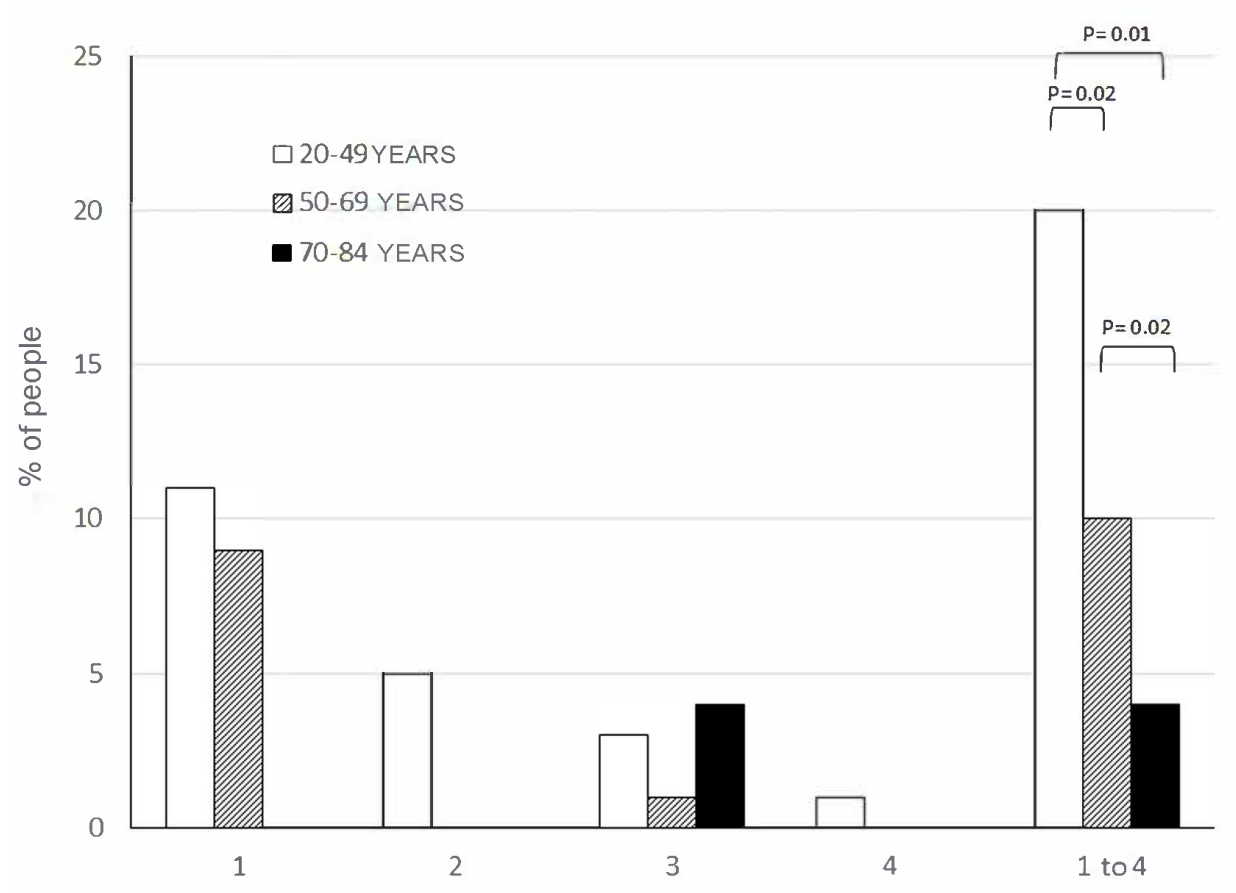

Figure 2. Results of answers given to question 5 (difficulty in swallowing medication) of the Eating Assessment Tool (EAT-10) in percentage of people, according to age group

As the total score of the instrument was analyzed, 400 subjects presented score $<3$, value considered as absence of dysphagia, and 39 presented score $\geq 3$, value indicating the possibility of dysphagia, according to the perception of the participants. Among those who presented EAT-10 score compatible with dysphagia, $28(72 \%)$ reported some degree of difficulty to swallow medications: 7 (18\%) reported degree $1 ; 7$ (18\%), degree 2; 12 (31\%), degree 3; and $2(5 \%)$, degree 4 . Eleven $(28 \%)$ obtained score indicative of swallowing difficulty $(\geq 3)$, but without impairing medication swallowing (score zero on question 5).

\section{DISCUSSION}

The swallowing of solid medications requires neuromotor control allowing the organization and coordination between medication and liquid and solid food that makes swallowing easier ${ }^{20}$.

In this study, $17 \%$ of the subjects considered healthy reported some degree of medications swallowing difficulty, results similar to studies carried out in other countries (Table 1): $16.5 \%$ in study carried out in Australia21; $14.8 \%$, in Belgium ${ }^{22} ; 14.0 \%$, in New
Zealand ${ }^{23} ; 10.4 \%$, in Jordan ${ }^{24}$; and 7.8\%, in England ${ }^{20}$. Marquis et al..$^{25}$, in a study conducted in Switzerland, wrote that $9 \%$ of the participants reported continuous medication swallowing difficulty, whereas $13.4 \%$ reported such difficulty at some moment of their lives. In a research carried out in the United States, $40 \%$ of the adult subjects reported this discomfort ${ }^{26}$. Differences in the results may be related to differences between populations and methodologies used. A paper assessed people who went to the drugstore to obtain or purchase medications ${ }^{15,21,22,24,25}$; another study included patients in primary healthcare ${ }^{14}$; another included people in waiting rooms waiting for medical care $^{13}$; and in a populational study, the sample was composed through a draw based on a list of voters ${ }^{23}$. Moreover, each assessment was made by means of questionnaires prepared by each research group. The results found in this investigation suggest that the difficulty in swallowing medications in the population studied is higher than that observed in other populations, maybe as a consequence of different instruments used in the assessment, or the different sensitivity in different populations. 
Table 1. Papers on medication swallowing difficulty

\begin{tabular}{ccccc}
\hline Reference & Year & Country & Total number of people & $\begin{array}{c}\text { Swallowing difficulty } \\
\text { (\%) }\end{array}$ \\
\hline Oad et al..$^{14}$ & 2018 & New Zealand & 40 & 57.0 \\
Tahaineh e et al. $^{23}$ & 2017 & Jordan & 1,250 & 10.4 \\
Liu et al. ${ }^{15}$ & 2016 & United Kingdom & 12 & 7.8 \\
Fields et al. ${ }^{13}$ & 2015 & United States & 50 & 50.0 \\
Lau et al. ${ }^{20}$ & 2015 & Australia & 369 & 16.5 \\
Schiele et al. & 2013 & Germany & 1,051 & 37.4 \\
Marquis et al. ${ }^{24}$ & 2013 & Switzerland & 410 & 22.4 \\
Mehuyset al. ${ }^{21}$ & 2012 & Belgium & 338 & 14.8 \\
Tordoff et al. ${ }^{22}$ & 2010 & New Zealand & 524 & 14.0 \\
\hline
\end{tabular}

In this study, when comparing the degree of swallowing difficulty between men and women, there was no significant difference. However, when comparing the absence and the presence of difficulty, regardless of the degree mentioned by the subject, there was significant difference, showing that more women had difficulties. A similar description was found on the study by Llorca, published in $2011^{26}$, in which twice the number of women reported discomfort in swallowing tablets, when compared to men. In the studies carried out in Germany ${ }^{12}$ and Norway ${ }^{27}$, the difficulty was also more frequent in women and in the younger people. A possible explanation to these findings would be the difference in sensitivity related to gender and aging. Papers assessing sensitivity in other situations demonstrated effects of gender and age ${ }^{28,29}$, which were more intense in women and in the younger people. The clarification of this hypothesis regarding dysphagia requires more specific studies.

Swallowing difficulties become more common as age advances ${ }^{8,11}$; thus, it was expected that medication swallowing difficulties would also be more frequent in older people. However, $14 \%$ of those aged between 50 and 69 years, and $20 \%$ of those aged between 20 and 49 years reported some degree of medication swallowing difficulty, similar to what is described on other studies ${ }^{16,26}$. In an investigation conducted with adolescents in Denmark, it was reported that the inability to swallow medications was related to its flavor and size, so that they either smashed, broke or took the along with food $^{30}$. Such adaptations are commonly made by patients and caregivers in order to facilitate the swallowing process $21,22,24,30$.

Along with the aging process, physiological alterations also take place, which may have an impact on the swallowing process. However, it is believed that medication swallowing is improved by repetitive experience and, therefore, by learning how to do $\mathrm{it}^{26,30,31}$. A study carried out in Norway encompassing all age groups showed that the patients' difficulty in swallowing tablets decrease sharply with age ${ }^{27}$.

Of the patients who reported medication swallowing difficulty, $72 \%$ presented symptoms compatible with the diagnosis of dysphagia, according to the EAT-10. These subjects are more prone to having difficulties in swallowing solid medications and reported greater degree of difficulty in comparison to those without dysphagia. There is the description of similar results, in which $34.6 \%$ of the patients reported difficulties in swallowing solid and liquid food, and a similar proportion (36.5\%) described difficulties in swallowing solid medications, even when taken along with liquid or pudding-like food ${ }^{12}$.

It's important to remember that most of the patients who reported difficulty in swallowing medications have no spontaneous dysphagia complaint. Hence, it's not possible to safely correlate these two processes. Such fact emphasizes the importance of identifying these symptomatic subjects, as well as making raising awareness in patients, caregivers and relatives regarding the necessary care and handling related to taking and giving medications ${ }^{14,31}$. The limitation of this investigation is due to the number of volunteers aged over 70 years. In this age group, it's more difficult to find totally asymptomatic people who take no medications. However, it's possible to consider that apparently healthy people in this stage of life have less medication swallowing difficulty when compared to younger people. It's also important to consider that $72 \%$ of those with EAT-10 $\geq 3$ had some degree of medication 
swallowing difficulty. This datum suggests that people who report medication swallowing difficulty must be assessed with the EAT-10, an evaluation for the possibility of dysphagia which is at the same time simple, quick, non-invasive and low-cost.

The limitation of this investigation is the inclusion of more women $(61.5 \%)$ than men $(38.5 \%)$ in the sample, which may have had an influence on the results.

\section{CONCLUSION}

Some degree of medication swallowing difficulty was reported by $17 \%$ of the population studied (people without diseases and with no spontaneous dysphagia complaint), with a higher frequency among women than among men, as well as among the younger people, when compared to the elderly.

\section{REFERENCES}

1. Shaw SM, Martino R. The normal swallow. Muscular and neurophysiological control. OtolaringolClin N Am. 2013;46(6):937-56.

2. Lang IM. Brain stem control of the phases of swallowing. Dysphagia. 2009;24(3):333-48.

3. Dantas RO, Kern MK, Massey BT, Dodds WJ, Kahrilas PJ, Brasseur JG et al. Effect of swallowed bolus variables on oral and pharyngeal phases of swallowing. Am J Physiol. 1990;258(5):G675-81.

4. Nascimento WV, Cassiani RA, Santos CM, Dantas RO. Effect of bolus volume and consistency on swallowing events duration in healthy subjects. J Neurogastroenterol Motil. 2015;21(1):78-82.

5. Dantas RO, Cassiani RA, Santos CM, Gonzaga GC, Alves LMT, Mazin SC. Effect of gender on swallow event duration assessed by videofluoroscopy. Dysphagia. 2009;24(3):280-4.

6. Pearlman AL, Schultz PG, Van Daele DJ. Effect of age, gender, bolus volume, and bolus viscosity on oropharyngeal pressure during swallowing. J Appl Physiol. 1993;75(1):33-7.

7. Alves LMT, Cassiani RA, Santos CM, Dantas RO. Gender effect on the clinical measurement of swallowing. ArqGastroenterol. 2007;44(3):227-9.

8. Clavé $P$, Shaker R. Dysphagia: current reality and scope of the problem. Nat Rev GastroenterolHepatol. 2015;12(5):259-70.

9. Namasivayam-McDonald AM, Barbon CEA, Steele $\mathrm{CM}$. A review of swallow timing in the elderly. PhysiolBehav. 2018;184:12-26.
10. Cook IJ. Oropharyngeal dysphagia. GastroenterolClin North Am. 2009;38(3):411-31.

11. Humbert IA, Robbins J. Dysphagia in the elderly. Phys Med ReabilClin North Am. 2008;19(4):853-66.

12. Schiele JT, Quinzler R, Klimm H, Pruszydlo MG, Haefeli WE. Difficulties swallowing solid oral dosage forms in a general practice population: prevalence, causes, andrelationship todosageforms. Eur $\mathrm{J}$ ClinPharmacol. 2013;69(4):937-48.

13. Fields J, Go JT, Schulze KS. Pill properties that cause dysphagia and treatment failure. CurrTher Res Clin Exp.2015;77:79-82.

14. Oad MA, Miles A, Lee A, Lambie A. Medicine administration in people withParkinson's disease in New Zealand: aninterprofessional, stakeholderdriven online survey. Dysphagia. 2019;34(1):119-28.

15. Liu F, Ghaffur A, Bains J, Hamdy S. Acceptabilityof oral solid medicines in olderadultswithand without dysphagia: a nested pilot validation questionnaire based observational study. Int $\mathrm{J}$ Pharm. 2016;512(2):374-81.

16. Schiele JT, Penner H, Schneider H, Quinzler $\mathrm{R}$, Reich $\mathrm{G}$, Wezler $\mathrm{N}$ et al. Swallowing tablets and capsules increases the risk of penetration and aspiration in patients with stroke-induced dysphagia. Dysphagia. 2015;30(5):571-82.

17. Belafsky PC, Mouadeb DA, Rees CJ, Pryor JC, Postma GN, Allen $\mathrm{J}$ et al. Validity and reliability of the Eating Assessment Tool (EAT-10). Ann Otol Rhinol Laryngol. 2008;117(12):919-24.

18. Gonçalves MIR, Remaili CB, Behlau M. Cross cultural adaptation of Brazilian version of the Eating Assessment Tool - EAT-10. CoDAS. 2013;25(6):601-4.

19. Rofes L, Arreola V, Mukherjee R, Clave P. Sensitivity and specificity of the eating assessment tool and the volume-viscosity swallow test for clinical evaluation of oropharyngeal dysphagia. NeurogastroenterolMotil. 2014;26(9):1256-65.

20. Uchimura EMT, Barcelos IHK, Paiva DB, Mourão LF, Crespo AN. Evaluation of the location of capsules swallowed with food during the pharyngeal phase triggering in asymptomatic adults. CoDAS. 2014;26(6):476-80.

21. Lau TLL, Steadman KJ, Mak M, Cichero JAY, Nissen LM. Prevalence of swallowing difficulties and medication modification in customers of community pharmacists. J PharmPract Res. 2015;45(1):18-23.

22. Mehuys E, Dupond L, Petrovic M, Christiaens T, Van Bortel L, Adriaens E et al. Medication 
management among home-dwelling older patients with chronic diseases: possible roles for community pharmacists. J Nutr Health Aging. 2012;16(8):721-6.

23. Tordoff JM, Bagge ML, Gray AR, Campbell AJ, Norris PT. Medicine-takingpractices in communitydwelling people aged $\geq 75$ years in New Zealand. Age Ageing. 2010;39(5):574-80.

24. Tahaineh L, Wazaify M. Difficulties in swallowing oral medications in Jordan. Int $\mathrm{J}$ ClinPharm. 2017;39(2):373-9.

25. Marquis J, Schneider M, Payot V, Cordonier A, Bugnon O, Hersberger KE et al. Swallowing difficulties with oral drugs among polypharmacy patients attending community pharmacies. Int $\mathrm{J}$ ClinPharm. 2013;35(6):1130-6.

26. Llorca PM. Discussion of prevalence and management of discomfort when swallowing pills: orodispersible tablets expand treatment options in patients with depression. TherDeliv. 2011;2(5):611-22.

27. Andersen O, Zweidorff OK, Hjelde T, Rodland EA. Problems when swallowing tablets. A questionnaire study from general practice. Tidsskr Nor Laegeforen. 1995;115(8):947-9.

28. Bassett JF. Disgust sensitivity accounts for some but not all gender differences in death attitudes. Omega (Westport). 2017;75(1):26-46.

29. Chen Z, Han J, Waddington G, Adams R, Witchalls J. Somatosensory perception sensitivity in voluntary postural sway movements: age, gender and sway effects magnitudes. Exp Gerontol. 2019;122(1):53-9.

30. Hansen DL, Tulinius D, Hansen EH. Adolescents' struggles with swallowing tablets: barriers, strategiesand learning. Pharm World Sci. 2008;30(1):65-9.

31. Lau TLL, Steadman KJ, Cichero JAY, Nissen LM. Dosage form modification and oral drug delivery in older people. Adv Drug Deliv Rev. 2018;135:75-84. 